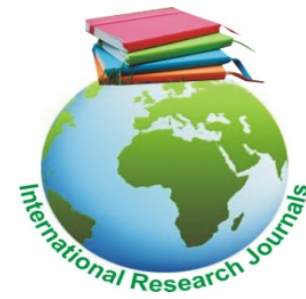

\title{
Case-control study of risk factors associated with preeclampsia in the Gaza Strip
}

\author{
Dr. Samar El-Nakhal \\ Al-Wehdah Street -Nutrition Department Ministry of Health - Gaza City, Gaza Strip - Palestinian Authority \\ Corresponding Author's E-mail: samarelnakhal@gmail.com Mobile: 00972599790196
}

\begin{abstract}
Aim: This study aimed to investigate risk factors associated with preeclampsia among registered pregnant women at primary health care centers in the Gaza Strip. Methods and materials: A case-control study was conducted in 2011 to investigate risk factors associated with preeclampsia in Gaza Strip. A total of 54 cases of preeclampsia were ascertained at four primary health care centers based on criteria defined by the World Health Organization. The study population included 162 pregnant women (54 cases and 108 controls). Results: Previous history of preeclampsia (OR=6.74, 95\%, Cl 2.89 to 15.72), hypertension (6.63, 1.29 to 34.03), maternal age exceeding 35 years $(4.9,2.07$ to 11.60) and education < 9 years were significantly associated with increased risk of preeclampsia. Moreover, young mothers $(1.36,0.37$ to 5.04$)$, primigravida $(1.54,0.70$ to 3.35$)$, pregnant with family history $(1.95,0.94$ to 4.07$)$, obese $(2.01,0.89$ to 4.51$)$ and diabetic pregnant women $(2.04,0.28$ to 14.88$)$ were more prone to develop preeclampsia. Living within an extended family, maternal education exceeding 9 years and maternal age between 18 and 35 years were protective factors. No statistical relationship could be concluded between maternal occupation and multiple pregnancy, and preeclampsia development. Conclusion: Previous and family history of preeclampsia, dietary related chronic diseases (obesity, diabetes mellitus and essential hypertension), being primigravida and increasing maternal age are risk factors that increased the risk of development of preeclampsia. Proper antenatal care and prompt management of dietary related chronic diseases are important in the early detection and management of preeclampsia.
\end{abstract}

Keywords: Preeclampsia, pregnant, primigravida, obesity, Gaza Strip

\section{LIST OF ABBREVIATIONS}

BMI: Body Mass Index

CDC: Centers for Disease Control and Prevention-Atlanta

Cl: Confidence Intervals

DM: Diabetes Mellitus

FBG: Fasting Blood Glucose

MmHg: Millimeter Mercury

MoH: Ministry of Health

OR: Odds Ratio

SPSS: Statistical Package for Social Sciences

UNRWA: United Nations Relief and Works Agency for Palestine Refugees

WHO: World Health Organization

\section{INTRODUCTION}

Pregnancy is a normal physiological process that is supposed to be an enjoyable time for mothers and their families. Despite of this, pregnancy can be associated with risk for both the mother and her baby, and even 
death. According to the World Health Organization (WHO), about 514,000 women die every year of pregnancy related causes, $99 \%$ of these deaths occur in the developing countries (WHO, 2007d). Death of a mother is a catastrophe indeed.

More than $80 \%$ of maternal deaths worldwide are due to five direct causes: hemorrhage, sepsis, unsafe abortion, pulmonary embolism and hypertensive diseases of pregnancy. The leading causes of maternal deaths in the United States are: hemorrhage, preeclampsia, sepsis and ectopic pregnancy (CDC, 2005).

According to the Palestinian Ministry of Health $(\mathrm{MoH})$, 7 and 14 maternal deaths were reported in the Gaza Strip during 2007 and 2008 respectively, two of these deaths during 2007 were due to preeclampsia $(\mathrm{MoH}, 2009)$. The leading causes of maternal deaths among Palestinian refugees were pregnancy induced hypertension, hemorrhage, pulmonary embolism, and heart diseases (Mousa and Madi, 2004).

The present study is mainly concerned with preeclampsia, which is defined according to the International Classification of Diseases, tenth revision (ICD-10) as a diastolic blood pressure of at least 90 $\mathrm{mmHg}$ on two or more consecutive occasions of at least four hours apart or a diastolic blood pressure of at least $110 \mathrm{mmHg}$ on any one occasion, plus proteinurea of at least $300 \mathrm{mg}$ per $24 \mathrm{hr}$ or > I+ on a urine dipstick (WHO, 1994a). Those should arise de novo after the $20^{\text {th }}$ week of pregnancy in a previously normotensive woman and resolving completely by the $6^{\text {th }}$ postpartum week. Moreover, edema is no longer considered a diagnostic criterion (Williams and Pridjian, 2007).

Preeclampsia is the most common complication of pregnancy affecting about $5-7 \%$ of all pregnancies globally. It is a serious disorder that can lead to low birth weight, premature labor, stillbirth and even death of the mother, so it represents a significant public health problem (Blenning, 2003; Williams and Pridjian, 2007). Pre-eclampsia is a leading cause of maternal death. The WHO estimates that every year, between 50,000 and 75,000 women die of this condition worldwide, as pregnancy induced hypertension is responsible for $12 \%$ of maternal deaths worldwide (WHO, 2005c).

The etiology for preeclampsia remains unknown. However, placental dysfunction or defective placentation may initiate systemic vasospasm, ischemia, and thrombosis that eventually damages maternal organs and causes placental infarction, intrauterine growth restriction and death (Williams and Pridjian, 2007). Risk factors associated with preeclampsia include primigravida, young ( $<18$ years), elderly (>35 years) and obese women, preexisting diseases such as diabetes mellitus (DM), essential hypertension and kidney diseases, previous history of preeclampsia (personal or family history) and other factors such as multiple pregnancy and molar pregnancy (WHO, 2000b; Reynolds et al., 2002; Campbell and Lees, 2006; Williams and Pridjian, 2007).

In the Gaza Strip, there is no accurate information about the status of preeclampsia as there is underdiagnosis and under-reporting of these cases. Additionally, no previous studies were conducted to investigate risk factors that can contribute to the development of preeclampsia. However, 2,229 cases of hypertension (essential hypertension and preeclampsia) were detected during pregnancy at health centers of the United Nations Relief and Works Agency for Palestine Refugees (UNRWA) in 2002 with an incidence of $7.4 \%$ (UNRWA, 2003).

This study aimed to investigate risk factors associated with preeclampsia among registered pregnant women at primary health care centers of the MoH in the Gaza Strip.

\section{METHODS}

The present case control study was conducted in the Gaza Strip from the $1^{\text {st }}$ of January 2011 up to the $30^{\text {th }}$ of April 2011. Cluster sampling was followed as four governmental centers (Rimal, Zaitoun, Deir El-Balah and Jabalia) were selected randomly. All newly registered pregnant women who were more than 20 gestational weeks suffering from preeclampsia were selected representing the cases. For each case (pregnant with preeclampsia) two controls were taken. The study population included 162 pregnant women (54 cases and 108 controls).

A permission letter was obtained from the $\mathrm{MoH}$. Confidentiality of subjects was maintained throughout the study and an informed consent was obtained from women who participated in the study. Data were collected using direct and indirect methods. Direct methods included measuring of height, weight and blood pressure of pregnant women, while indirect methods were conducted through structured interviewed questionnaire (Annex 1).

Statistical Package for Social Sciences (SPSS) version 13 was used for data entry and analysis. Crude odds ratio with $95 \%$ confidence intervals $(\mathrm{Cl})$ were used for statistical analysis. A pilot study was conducted to obtain more information to assess the feasibility of the study, where some items of the questionnaire were modified.

In the present study, women who have preeclampsia according to the ICD-10 represent the dependent variable. Independent variables include maternal age, mother's education and occupation, type of family, preexisting maternal conditions such diabetes mellitus or essential hypertension, obesity, parity, type of pregnancy (single or multiple), previous history of preeclampsia and family history of preeclampsia.

Maternal age at the beginning of pregnancy was 
Table 1: Comparison between cases and controls by demographic and socioeconomic status

\begin{tabular}{|c|c|c|c|c|c|}
\hline Variable & Cases & $\%$ & Controls & $\%$ & OR, 95\% Cl \\
\hline \multicolumn{6}{|l|}{ Age of mothers: } \\
\hline$<18$ years & 4 & $7.4 \%$ & 6 & $5.6 \%$ & $\begin{array}{c}\mathrm{OR}=1.36 \\
95 \% \mathrm{Cl} 0.37 \text { to } 5.04 \\
\mathrm{P}=0.65\end{array}$ \\
\hline 18-35 years & 32 & $59.3 \%$ & 92 & $85.2 \%$ & $\begin{array}{c}\mathrm{OR}=0.25 \\
95 \% \mathrm{Cl} 0.12 \text { to } 0.54 \\
\mathrm{P}=0.0004\end{array}$ \\
\hline$>35$ years & 18 & $33.3 \%$ & 10 & $9.2 \%$ & $\mathrm{OR}=4.9$ \\
\hline Total & 54 & $100 \%$ & 108 & $100 \%$ & $\begin{array}{c}95 \% \mathrm{Cl} 2.07 \text { to } 11.60 \\
\mathrm{P}=0.0003\end{array}$ \\
\hline Years of maternal education: & & & & & Education< 9 yrs \\
\hline 0 & 0 & $0 \%$ & 2 & $1.9 \%$ & $\mathrm{OR}=2.12$ \\
\hline 1-6 years & 10 & $18.5 \%$ & 16 & $14.8 \%$ & $95 \% \mathrm{Cl} 1.09$ to 4.11 \\
\hline $7-9$ years & 22 & $40.8 \%$ & 26 & $24.1 \%$ & $\begin{array}{c}\mathrm{P}=0.027 \\
\text { Education }>9 \text { yrs }\end{array}$ \\
\hline 10-12 years & 16 & $29.6 \%$ & 52 & $48.1 \%$ & $\mathrm{OR}=0.47$ \\
\hline$>12$ years & 6 & $11.1 \%$ & 12 & $11.1 \%$ & $95 \% \mathrm{Cl} 0.24$ to 0.92 \\
\hline Total & 54 & $100 \%$ & 108 & $100 \%$ & $P=0.027$ \\
\hline \multicolumn{6}{|l|}{ Occupation: } \\
\hline Housewife & 54 & $100 \%$ & 108 & $100 \%$ & $\mathrm{OR}=1$ \\
\hline Others & 0 & $0.0 \%$ & 0 & $0.0 \%$ & \\
\hline Total & 54 & $100 \%$ & 108 & $100 \%$ & \\
\hline \multicolumn{6}{|l|}{ Type of family: } \\
\hline Extended family & 18 & $33.3 \%$ & 44 & $40.7 \%$ & $\mathrm{OR}=0.73$ \\
\hline Nuclear family & 36 & $66.6 \%$ & 64 & $59.3 \%$ & $95 \% \mathrm{Cl} 0.37$ to 1.44 \\
\hline Total & 54 & $100 \%$ & 108 & $100 \%$ & $P=0.36$ \\
\hline
\end{tabular}

Table 2: Comparison between cases and controls by obstetric factors

\begin{tabular}{|c|c|c|c|c|c|}
\hline Variable & Cases & $\%$ & Controls & $\%$ & OR, 95\% Cl, P value \\
\hline \multicolumn{6}{|l|}{ Parity: } \\
\hline Primigravida & 14 & $25.9 \%$ & 20 & $18.5 \%$ & \multirow{3}{*}{$\begin{array}{c}\text { OR }=1.54 \\
95 \% \mathrm{Cl} 0.70 \text { to } 3.35 \\
\mathrm{P}=0.27\end{array}$} \\
\hline Multigravida & 40 & $74.1 \%$ & 88 & $81.5 \%$ & \\
\hline Total & 54 & $100 \%$ & 108 & $100 \%$ & \\
\hline \multicolumn{6}{|l|}{ Type of pregnancy: } \\
\hline Single pregnancy & 4 & $7.4 \%$ & 8 & $7.4 \%$ & \multirow[t]{3}{*}{ OR= 1} \\
\hline Multiple pregnancy & 50 & $92.6 \%$ & 100 & $92.6 \%$ & \\
\hline Total & 54 & $100 \%$ & 108 & $100 \%$ & \\
\hline \multicolumn{6}{|c|}{ Previous history of preeclampsia: } \\
\hline Yes & 22 & $40.7 \%$ & 10 & $9.3 \%$ & \multirow{3}{*}{$\begin{array}{c}\text { OR }=6.74 \\
95 \% \mathrm{Cl} 2.89 \text { to } 15.72 \\
\mathrm{P}<0.0001\end{array}$} \\
\hline No & 32 & $59.3 \%$ & 98 & $90.7 \%$ & \\
\hline Total & 54 & $100 \%$ & 108 & $100 \%$ & \\
\hline \multicolumn{6}{|c|}{ Family history of preeclampsia: } \\
\hline Yes & 18 & $33.3 \%$ & 22 & $20.4 \%$ & \multirow{3}{*}{$\begin{array}{c}\mathrm{OR}=1.95, \\
95 \% \mathrm{Cl} 0.94 \text { to } 4.07 \\
\mathrm{P}=0.07\end{array}$} \\
\hline No & 36 & $66.7 \%$ & 86 & $79.6 \%$ & \\
\hline Total & 54 & $100 \%$ & 108 & $100 \%$ & \\
\hline
\end{tabular}

categorized into three groups: <18, 18-35, and $>35$ years. Mothers education was categorized into five groups: none, elementary, preparatory, secondary and, university. Types of family included two categories: nuclear and extended. Maternal height and weight were recorded at the first antenatal visit (between $6^{\text {th }}$ and $10^{\text {th }}$ week of gestation) and Body Mass Index (BMI) was categorized into four groups: underweight $(\mathrm{BMI}<18.5)$, normal weight (BMI 18.5-24.9), overweight (BMI 25-
29.9) and obese (BMI $=$ or $>30)$. Essential or chronic hypertension was ascertained as blood pressure higher than $140 / 90 \mathrm{mmHg}$ started before 20 weeks of gestation (Reynolds et al., 2002; Williams and Pridjian, 2007; Tallia et al. 2009).

\section{RESULTS AND ANALYSIS}

Results were summarized using three tables (tables 1-3). 
Table 3: Comparison between cases and controls by dietary related chronic diseases

\begin{tabular}{|c|c|c|c|c|c|}
\hline Variable & Cases & $\%$ & Controls & $\%$ & OR, 95\% Cl, P value \\
\hline \multicolumn{6}{|c|}{ Obesity (BMI > 30): } \\
\hline Yes & 14 & $25.9 \%$ & 16 & $14.8 \%$ & \multirow{3}{*}{$\begin{array}{c}\text { OR }=2.01 \\
95 \% \text { Cl } 0.89 \text { to } 4.51 \\
P=0.089\end{array}$} \\
\hline No & 40 & $74.1 \%$ & 92 & $85.2 \%$ & \\
\hline Total & 54 & $100 \%$ & 108 & $100 \%$ & \\
\hline \multicolumn{6}{|c|}{ History of hypertension: } \\
\hline Yes & 6 & $11.1 \%$ & 2 & $1.9 \%$ & \multirow{3}{*}{$\begin{array}{c}\text { OR }=6.63, \\
95 \% \text { Cl } 1.29 \text { to } 34.03 \\
P=0.024\end{array}$} \\
\hline No & 48 & $88.9 \%$ & 106 & $98.1 \%$ & \\
\hline Total & 54 & $100 \%$ & 108 & $100 \%$ & \\
\hline \multicolumn{6}{|c|}{ History of Diabetes (DM): } \\
\hline Yes & 2 & $3.7 \%$ & 2 & $1.9 \%$ & \multirow{3}{*}{$\begin{array}{c}\mathrm{OR}=2.04 \\
95 \% \mathrm{Cl} 0.28 \text { to } 14.88 \\
\mathrm{P}=0.48\end{array}$} \\
\hline No & 52 & $96.3 \%$ & 106 & $98.1 \%$ & \\
\hline Total & 54 & $100 \%$ & 108 & $100 \%$ & \\
\hline
\end{tabular}

\section{DISCUSSION}

The present study indicates that maternal age less than 18 years was associated with increased risk of preeclampsia $(\mathrm{OR}=1.36,95 \%, \mathrm{Cl} 0.37$ to 5.04$)$. In addition, maternal age exceeding 35 years was significantly associated with preeclampsia $(\mathrm{OR}=4.9$, $95 \%, \mathrm{Cl} 2.07$ to 11.60$)$. Similarly, Conde-Agudelo and Belizan (2000) and Chamberlain and Morgan (2002) concluded that women who were $>35$ years are more prone to develop preeclampsia. In contrast to those, Sibai (1997) found that maternal age was not a statistically significant risk factor of preeclampsia. The higher risk of preeclampsia among women aged $>35$ years could be attributed to the placental ischemia secondary to the increasing sclerotic lesions in the myometrial arteries.

With respect to education, it was found that maternal education more than 9 years formed a significant protective factor against the development of preeclampsia $(\mathrm{OR}=0.47,95 \%, \mathrm{Cl} 0.24$ to 0.92$)$, while maternal education less than 9 years was a statistically significant risk factor of preeclampsia $(\mathrm{OR}=2.12,95 \%, \mathrm{Cl}$ 1.09 to 4.11 ).

Moreover, living within an extended family was found to be a protective factor against the development of preeclampsia $(\mathrm{OR}=0.73,95 \%, \mathrm{Cl} 0.37$ to 1.44$)$. This result contradicted the expectation of the researcher, as living within extended families exposes pregnant women to various social, physical and psychological stressors that were supposed to increase the risk of preeclampsia. Further studies with larger sample size should be conducted to re-assess the role of family type (extended or nuclear) as a risk factor for preeclampsia. An increased risk of preeclampsia among primigravida was reported in this study $(\mathrm{OR}=1.54,95 \%, \mathrm{Cl} 0.70$ to 3.35$)$. This effect has been widely studied (Martin et al. 2000; Duckitt and Harrington 2005; Campbell and Lees 2006). The researchers attributed this finding to the maternal first exposure to trophoblast as being of fetal origin.

The present study revealed that history of preeclampsia confers the highest risk for preeclampsia, as previous history of preeclampsia was significantly associated with nearly sevenfold more risk of developing preeclampsia (OR=6.74, 95\%, $\mathrm{Cl} 2.89$ to 15.72$)$. There is consensus in the literature regarding the role of previous history of preeclampsia as a contributing factor for preeclampsia. Broughton (2001), Mostello et al. (2002) and Duckitt and Harrington (2005) all addressed this relationship.

Moreover, this study addressed the association between family history of preeclampsia and the development of preeclampsia (OR=1.95, 95\%, $\mathrm{Cl} 0.94$ to 4.07). This association was also reported by Broughton (2001) and Duckitt and Harrington (2005).

It was concluded that dietary related chronic diseases such as obesity, preexisting diabetes mellitus and essential hypertension were considerable risk factors for the development of preeclampsia $(\mathrm{OR}=2.01,95 \%, \mathrm{Cl}$ 0.89 to $4.51, \mathrm{OR}=2.04,95 \%, \mathrm{Cl} 0.28$ to 14.88 and OR=6.63, $95 \%, \mathrm{Cl} 1.29$ to 34.03 respectively). The arrived at conclusion is similar to that of other researchers such as Thadhani et al. (1999), CondeAgudelo and Belizan (2000) and Mostello et al. (2002) who reported that obese women were more prone to the development of preeclampsia.

Obesity might act through insulin resistance or increased sympathetic activity; both have been associated with hypertensive disorders of pregnancy including preeclampsia. In addition, women who develop preeclampsia usually have hyperlipidemia early in pregnancy. In this case, the hyperlipidemia might favor the production of lipid peroxides and alter the balance of vasoactive compounds leading to endothelial cell dysfunction and vasoconstriction that are hallmarks of preeclampsia (Conde-Agudelo and Belizan 2000).

Results of the present study did not demonstrate statistical association between the type of pregnancy (single or multiple) and the development of preeclampsia $(\mathrm{OR}=1)$. Moreover, all women included in the sample were housewives, so no comment concerning this topic could be concluded. To evaluate the role of these factors, further studies should be carried out. 


\section{CONCLUSION AND RECOMMENDATIONS}

Previous history of preeclampsia, family history of preeclampsia, dietary related chronic diseases (obesity, preexisting diabetes mellitus and essential hypertension), being primigravida and increasing maternal age $(>35$ years) maternal education $<9$ years are risk factors that increased the risk of development of preeclampsia. Proper antenatal care, especially for pregnant women with previous history of preeclampsia, and prompt management of dietary related chronic diseases are important in the early detection and management of preeclampsia. Further studies including larger samples are recommended.

\section{Conflict of interest}

The study was self funded and the author states that there was no conflict of interest.

\section{REFERENCES}

Blenning CE (2003). Obstetric complications during pregnancy: Taylor $R B$, editor. Family medicine principles and practice $6^{\text {th }}$ edition. New York: Springer. p. 123-124.

Broughton PF(2001). Risk factors for preeclampsia N. Engl J Med. 344:925-926. DOI: 10.1056/NEJM200103223441209.

Campbell S, Lees C (2006). Obstetrics By Ten Teachers, $18^{\text {th }}$ edition. Baker PN, editor. London: Arnold.

Centers for Disease Control and Prevention (2005). "National Agenda for Public Health Action: A National Public Health Initiative on Diabetes and Woman's Health". http://www.cdc.govldiabetes/pubs/action/facts.htm\#l. [Accessed $24^{\text {th }}$ March 2010]. Chamberlain G, Morgan M (2002). ABC of antenatal care, $4^{\text {th }}$ edition. London: BMJ Publishing Group.

Conde-Agudelo A, Belizan JM (2000). Risk factors for pre-eclampsia in a large cohort of Latin American and Caribbean women. $\mathrm{Br} \mathrm{J}$ Obstet Gynecol. 107(1):75-83.
Duckitt K, Harrington D (2005). Risk factors for pre-eclampsia at antenatal booking: Systematic review of controlled studies. BMJ. 330(7491):565. [PMC free article] [PubMed]

Martin CL, Hall MH, Campbell DM (2000). The effect of smoking on preeclampsia in twin pregnancy. Br J Obstet Gynecol. 107(6):745-49.

Ministry of Health (2009). The status of health in Palestine: Annual report 2008. Ramallah: Ministry of Health.

Mostello D, Catlin TK, Holcomb WL, Roman L, Leet T (2002). Preeclampsia in the parous woman: who is at risk? Am J Obstet Gynecol. 187(2):425-9.

Mousa F, Madi H (2004). UNRWA Study: Maternal Mortality Among Palestine Refugee Women. Gaza.

Reynolds C, Mabie WC, Sibai BM (2002). Hypertensive states of pregnancy. In: Decherney A, Nathan L, editors. Current obstetric and gynecologic diagnosis and treatment, $9^{\text {th }}$ edition. Lange/McGraw-Hill. p. 338-41.

Sibai BM (1997). Risk factors associated with preeclampsia in healthy nulliparous women. Am J Obstet Gynecol. 177:1003-1010.

Tallia AF, Scherger JE, Dickey NW (2009). Swanson's family practice review: A Problem-Oriented Approach, $6^{\text {th }}$ edition. Philadelphia: Mosby Inc. p. 503-507.

Thadhani R, Stampfer MJ, Hynter DJ, Manson JE, Solomon CG, Curhan GC (1999). High body mass index and hypercholesterolaemia: Risk of hypertensive disorders of pregnancy. Obstet Gynecol. 94:543-50. [PubMed]

United Nations Relief and Works Agency for Palestine Refugees, UNRWA (2003). Annual report on hypertension and diabetes cases during pregnancy 2002. Gaza: UNRWA.

Williams DE, Pridjian G. Obstetrics (2007). In: Rakel RE, Rakel DP, editors. Textbook of Family Medicine, $7^{\text {th }}$ edition. Saunders. p. 373380.

World Health Organization (1994a). The international classification of diseases and related health problems, $10^{\text {th }}$ revision (ICD-10). Geneva: World Health Organization.

World Health Organization (2000b). Technical instruction series: Prevention and control of non-communicable diseases. Geneva: World Health Organization.

World Health Organization (2005c). Making pregnancy safer: A framework for strategic directions for accelerating the reduction of maternal mortality in the Eastern Mediterranean countries. Geneva: World Health Organization.

World Health Organization (2007d). Maternal mortality in 2005: Estimates developed by WHO, UNICEF, UNFPA and the World Bank. Geneva: World Health Organization. 